\title{
KINERJA OPERASIONAL PELAYANAN TERMINAL KABUPATEN GRESIK
}

\section{Anak Agung Sagung Alit Widyastuty}

\author{
Program Studi Perencanaan Wilayah dan Kota \\ Universitas PGRI Adi Buana Surabaya \\ Email : adityawirayudha@yahoo.com
}

\begin{abstract}
Abstrak
Terminal sebagai prasarana perhubungan darat yang sangat penting, yaitu sebagai tempat untuk menaikkan dan menurunkan penumpang serta sebagai tempat persinggahan bagi bus-bus ditengah perjalanannya. Fungsi utama dari terminal yakni sebagai penyedia fasilitas masuk dan keluar dari obyek-obyek yang akan diangkut, penumpang atau barang, menuju dan dari sistem. Sesuai dengan fungsi terminal yang berperan dalam menunjang tersedianya jasa transportasi yang sesuai dengan tingkat kebutuhan, maka keberadaan terminal perlu direncanakan dengan baik agar dapat mengefektifkan dan mengoptimalkan kinerja dari terminal. Fenomena yang terjadi saat ini adalah, banyak calon penumpang dan penumpang yang naik dan turun dari mobil angkutan umum berada di luar terminal sehingga dapat menyebabkan macet, dan rawan kecelakaan. Pendekatan rancangan penelitian dengan menggunakan Deskriptif Kualitatif. Populasi penelitian merupakan sopir bis dan calon penumpang yang ada di Terminal Bunder. Jumlah sampel yang diambil adalah 22 responden yang berprofesi sebagai sopir dan 44 responden berasal dari calon penumpang yang ada di dalam Terminal Bunder Gresik. Analisis penelitian yang digunakan adalah analisis kinerja operasional pelayanan terminal bunder berupa sarana dan prasarana serta pola pergerakan sirkulasi terminal, waktu tunggu dan juga karakteristik sopir dan calon penumpang. Hasil dari penelitian ini adalah melakukan evaluasi kinerja terminal yang ada di Kabupaten Gresik dan juga melihat penyebab permasalahan yang terjadi selama ini dilapangan. Sehingga kedepannya dengan Dinas yang terkait dalam hal ini adalah Dinas Perhubungan dapat merencanakan dan menata eksisting dari terminal sehingga dapat mendukung aktivitas kota dan sesuai dengan para calon penumpang dan penumpang terminal
\end{abstract}

Kata kunci :

\section{PENDAHULUAN}

Terminal sebagai prasarana perhubungan darat yang sangat penting, yaitu sebagai tempat untuk menaikkan dan menurunkan penumpang serta sebagai tempat persinggahan bagi bus-bus ditengah perjalanannya. Fungsi utama dari terminal yakni sebagai penyedia fasilitas masuk dan keluar dari obyek-obyek yang akan diangkut, penumpang atau barang, menuju dan dari sistem. Sesuai dengan fungsi terminal yang berperan dalam menunjang tersedianya jasa transportasi yang sesuai dengan tingkat kebutuhan, maka keberadaan terminal perlu direncanakan dengan baik agar dapat mengefektifkan dan mengoptimalkan kinerja dari terminal.

Menurut Suwardjoko Warpani (Pratoyo A., 2001: 16) definisi terminal adalah titik simpul dari berbagai moda angkutan, sebagai titik perpindahan penumpang penumpang dari berbagai moda ke suatu moda, juga suatu titik tujuan atau titik akhir orang setelah turun melanjutkan berjalan kaki ke tempat kerja, rumah atau pasar, dengan kata lain terminal adalah sebagai titik henti

Berdasarkan Studi Direktorat Jenderal Perhubungan Darat (1994: 95) fungsi terminal transportasi jalan dapat ditinjau dari 4 unsur :

1. Titik konsentrasi penumpang dari segala arah yang berkumpul atau menuju ke sana, karena tujuan perjalanan di sekitar terminal atau yang akan berganti kendaraan.

2. Titik dispersi, yaitu tempat penyebaran penumpang ke segala penjuru kota atau keluar kota, atau ke beberapa tujuan khusus seperti airport,stasiun KA, dsb.

3. Titik tempat penumpang berganti moda angkutan.

4. Pusat pelayanan penumpang untuk naik dan turun kendaraan, menunggu, membeli karcis, dan beberapa keperluan yang bersangkutan dengan perjalanan.

5. Tempat untuk memproses kendaraan dan muatan 
Manfaat yang akan diperoleh dengan adanya terminal (Direktorat Jenderal Perhubungan Darat, 1994: 93) :

1. Sebagai tempat yang secara langsung dapat diketahui oleh penumpang sebagai tempat bertemunya berbagai jenis angkutan umum.

2. Sebagai tempat yang mudah untuk melakukan transfer antar berbagai moda dan pelayanan.

3. Sebagai fasilitas informasi bagi penumpang.

4. Sebagai tempat untuk mengendalikan pengoperasian angkutan.

5. Menghilangkan kendararaan umum berhenti di sembarang tempat dalam jangka waktu yang lama ('ngetem` di jalan).

Berdasarkan jenis materi yang diangkut, terminal dibedakan menjadi 2 (Kep. Menhub.

No. 31 tahun, Pasal 1) :

1. Terminal penumpang

Terminal penumpang adalah prasarana transportasi jalan untuk keperluan menurunkan dan menaikkan penumpang, perpindahan intra dan/atau antar moda transportasi serta mengatur kedatangan dan pemberangkatan angkutan umum.

2. Terminal barang

Terminal barang adalah prasarana transportasi bagi keperluan perpindahan barang dan pengiriman barang.
Berdasarkan Kep. Menhub No. 31 tahun 1995 Pasal 2, tentang Tipe dan Fungsi Terminal, mengklasifikasikan terminal penumpang menjadi tiga tipe, yaitu :

1. Tipe A, berfungsi melayani kendaraan untuk angkutan umum antar kota dan antar propinsi (AKAP) dan/atau angkutan lintas batas negara, angkutan antar kota dalam propinsi (AKDP), angkutan dalam kota (ADK) dan angkutan pedesaan (ADES)

2. Tipe $B$, berfungsi melayani angkutan antar kota dalam propinsi (AKDP), angkutan dalam kota (ADK) dan/atau angkutan pedesaan (ADES).

3. Tipe $\mathrm{C}$, berfungsi melayani angkutan dalam kota (ADK), dan/atau angkutan pedesaan (ADES)

Sedangkan terminal penumpang berdasarkan tingkat pelayanan yang dinyatakan dengan jumlah arus minimum kendaraan per satu satuan waktu mempunyai cirri-ciri sebagai berikut :

1. Terminal tipe $A: 50-100$ Kendaraan

2. Terminal tipe $B: 25-50$ Kendaraan

3. Terminal tipe $C: 25 \quad$ Kendaraan

Prasarana yang harus disediakan adalah sedemikian sehingga mampu mengantisipasi pelayanan ataupun pergerakan seperti yang dijelaskan pada Tabel berikut:

Tabel .1 Komponen Prasarana Yang Diperlukan Untuk Setiap Aktifitas Yang Terjadi Di Dalam

\begin{tabular}{|c|c|c|}
\hline No & Aktifitas & $\begin{array}{c}\text { Komponen Prasarana } \\
\text { yang Dibutuhkan }\end{array}$ \\
\hline 1 & Kedatangan bus dari luar terminal & Lajur bus \\
\hline 2 & Naiknya penumpang ke bus & Platform/berth/bus bay \\
\hline 3 & Turunnya penumpang dari bus & Platform/berth/bus bay \\
\hline 4 & Bus menunggu penumpang naik/turun & Platform/berth/bus bay \\
\hline 5 & Penumpang menunggu bus & $\begin{array}{l}\text { Platform atau ruang tunggu yang } \\
\text { dilengkapi tempat duduk }\end{array}$ \\
\hline 6 & Penumpang transfer bus & Platform/berth/bus-bay \\
\hline 7 & Pembelian tiket & Kios tiket \\
\hline 8 & Perawatan bus ringan & Platform khusus/bengkel kecil \\
\hline 9 & Penyimpanan bus & Garasi terbuka/tertutup \\
\hline 10 & Park \& Ride & Areal parkir tertutup \\
\hline 11 & Kiss \& Ride & Lajur/platform untuk kendaraan/taxi \\
\hline
\end{tabular}

Terminal bus lama yang dimiliki Kabupaten Gresik sebelum Th. 1997 adalah Terminal Bus Sidomoro yang berada di Jl. Veteran, Kecamatan Gresik. Latar belakang relokasi terminal lama dikarenakan terminal sudah tidak dapat menampung perkembangan armada dan penumpang yang semakin meningkat dengan luasan terminal yang relatif kecil untuk standar terminal tipe $\mathrm{B}$ yaitu hanya $1,3 \mathrm{Ha}$.

Memperhatikan kondisi yang semakin serat dan lokasi yang terbatas, 
sehingga dilakukan relokasi terminal bus ke pinggiran kota yaitu di JI. Dr. Wahididn Sudirohusodo, Kecamatan Cerme, dengan nama Terminal Bunder yang beroperasi tahun 1997. Pemindahan lokasi terminal bus bagi Pemerintah Kabupaten Gresik ini dengan harapan dapat menanggulangi kemacetan dalam kota, meningkatkan kapasitas terminal, meningkatkan pelayanan, pemerataan pembangunan dan meningkatkan pendapatan asli daerah.

Hasil wawancara dengan sopir bus dan pengamatan awal rata-rata tiap hari bus yang masuk ke Terminal Bunder hanya mendapat 2 penumpang saja, bahkan tidak mendapat penumpang. Selain itu, Terminal Bunder tidak memiliki jadwal keberangkatan dan kedatangan bus. Ditambah lagi bus-bus yang masuk ke terminal ngetem terlalu lama karena sepinya penumpang. Demikian juga ruang tunggu penumpang acapkali terlihat kosong. Sepinya Terminal Bunder dari pengunjung mengakibatkan banyak penyedia jasa yang menutup dagangannya. Dari hasil pengamatan awal kios yang masih buka di Terminal Bunder hanya 35\% saja dan sebagian besar agen travel. Fasilitas Terminal Bunder yang kurang terawat dan banyak fasilitas yang tidak berfungsi dengan semestinya menambah keengganan penumpang bus untuk ke Terminal Bunder. Kondisi ini mengakibatkan berkurangnya fungsi dan manfaat dari Terminal Gresik.

Melihat kondisi tersebut, perlu dilakukan studi untuk mengevaluasi kinerja Terminal Bunder. Dengan demikian, strategi yang sesuai bagi pengembangan Terminal Bunder dapat diidentifikasi sesuai dengan analisis perencanaan transportasi untuk menuju kepada tercapainya efektifitas dan pengoptimalan kinerja Terminal Bus Bunder.

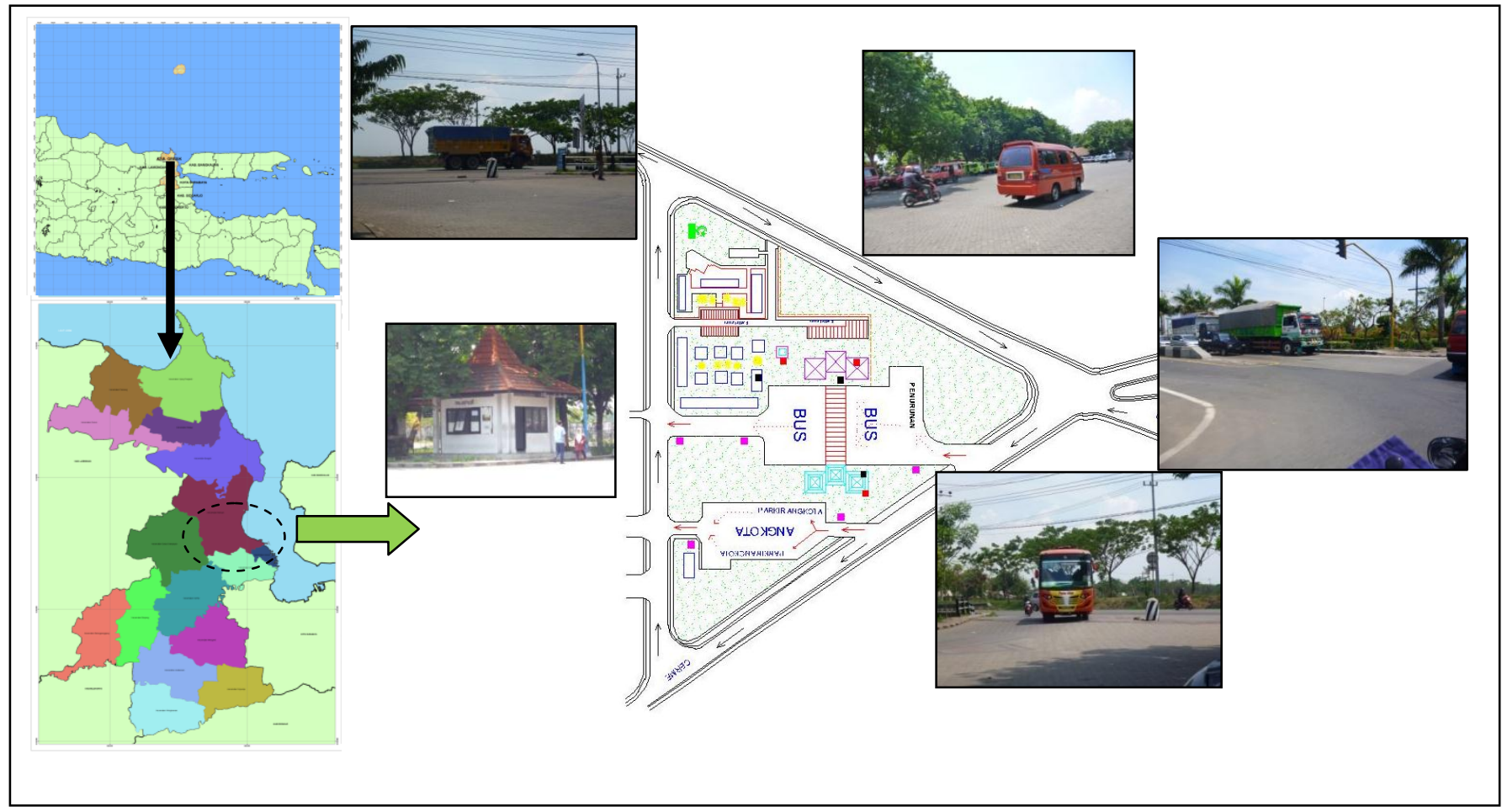

Gambar 1. Peta lokasi dan layout terminal Bunder Gresik.

Identifikasi permasalahan dalam penelitian ini adalah:

1. Penumpang bus kurang memenfaatkan Terminal Bunder sebagai tempat naik turunnya penumpang bus, dimana keadaan terminal acapkali terlihat kosong dan jumlah penumpang bus yang sedikit.
2. Fasilitas Terminal Bunder yang tidak berfungsi sepenuhnya baik dari aspek fisik dan non fisik, sehingga terminal terkesan kurang terawat dan suasana terminal menjadi kurang nyaman.

3. Lebih jauh lagi, kondisi tersebut dapat mengakibatkan berkurangnya nilai manfaat terminal bagi pemerintah daerah karena menurunnya pendapatan 
terminal, selain itu juga mengurangi nilai manfaat bagi pengguna lain seperti para penyedia jasa contohnya antara lain: para pedagang dan agen travel di Terminal Bunder.

Dari identifikasi permasalahan tersebut, dapat dirumuskan permasalahan yang nantinya akan diidentifikasikan strategi yang sesuai dengan analisis yang akan dilakukan dalam penelitian, yaitu:

1. Bagaimanakah kinerja operasional Terminal Bunder di Kabupaten Gresik?

2. Apa penyebab dari permasalahan yang timbul di Termina Bunder di Kabupaten Gresik?

Tujuan Dari Penelitian ini adalah :

1. Mengevaluasi Kinerja Operasional Terminal di Kabupaten Gresik.

2. Menemukan permasalahan yang timbul di Terminal Kabupaten Gresik

\section{METODE PENELITIAN}

Rancangan penelitian yang digunakan adalah dengan pendekatan
Deskriptif Kualitatif. Dengan menjabarkan dari aspek Spasial, Aspek Teknis dan Aspek penyebab permasalahan di terminal Bunder Gresik.

Populasi dari penelitian ini adalah sopir angkutan bis yang masuk dan keluar terminal juga dengan calon penumpang yang sedang menunggu di area tunggu terminal. Perhitungan pengambilan dengan metode sampling acak sederhana ini sebesar $10 \%$ dari jumlah populasi dianggap sudah mewakili. Sampel yang digunakan untuk sopir adalah $10 \%$ dari total bus yang masuk Terminal Bunder dan untuk masyarakat/penumpang sampel yang dianggap mewakili yaitu $2 \times$ jumlah sopir bus. Jumlah rata-rata bus yang masuk sebesar 217 bus, jadi total sampel sopir sebesar 21,7 responden. Untuk kemudahan perhitungan, sampel sopir dibulatkan sebesar 22 responden. Dengan demikian sampel penumpang sebesar 44 responden. Untuk lebih jelasnya akan di jabarkan pada tabel 2 di bawah ini.

Tabel. 2 tabel desain survey

\begin{tabular}{|c|c|c|c|c|c|c|}
\hline No. & Tujuan & Variabel & Sub Variabel & Sumber Data & Cara Survei & Metode \\
\hline 1. & $\begin{array}{l}\text { Mengetahui } \\
\text { aspek } \\
\text { spasial }\end{array}$ & $\begin{array}{l}\text { Kebijakan } \\
\text { tata ruang }\end{array}$ & $\begin{array}{l}\text { Kebijakan } \\
\text { penggunaan } \\
\text { lahan }\end{array}$ & $\begin{array}{l}\text { RTRW dan } \\
\text { RTRK }\end{array}$ & $\begin{array}{l}\text { Survei } \\
\text { sekunder } \\
\text { dan primer }\end{array}$ & $\begin{array}{l}\text { Analisis } \\
\text { Deskriptif } \\
\text { Kualitatif }\end{array}$ \\
\hline \multirow[t]{2}{*}{2.} & \multirow[t]{2}{*}{$\begin{array}{l}\text { Mengetahui } \\
\text { tingkat } \\
\text { pelayanan } \\
\text { terminal }\end{array}$} & $\begin{array}{l}\text { Karekteristi } \\
\mathrm{k} \\
\text { penumpan } \\
\text { g bus }\end{array}$ & $\begin{array}{l}\text { - Volume } \\
\text { penumpang. } \\
\text { - Waktu tunggu } \\
\text { penumpang. } \\
\text { - Pola } \\
\text { perjalanan } \\
\text { (asal tujuan) } \\
\text { penumpang }\end{array}$ & $\begin{array}{l}\text { - Hasil } \\
\text { pengamatan } \\
\text { di lapangan. } \\
\text { - hasil } \\
\text { wawancara } \\
\text { penupang. }\end{array}$ & Survei primer & $\begin{array}{l}\text { Analisis } \\
\text { Deskriptif } \\
\text { Kualitatif }\end{array}$ \\
\hline & & $\begin{array}{l}\text { Kesesuaia } \\
\mathrm{n} \text { fasilitas } \\
\text { terminal }\end{array}$ & $\begin{array}{l}\text { - Standar } \\
\text { Terminal. }\end{array}$ & $\begin{array}{l}\text { - data jenis } \\
\text { fasilitas di } \\
\text { Terminal } \\
\text { Bunder } \\
\text { - hasil } \\
\text { wawancara. } \\
\text { - Kep. Men. } \\
\text { Hub. No. } 31 \\
\text { Th. 1995 }\end{array}$ & Survei primer & $\begin{array}{l}\text { Analisis } \\
\text { Deskriptif } \\
\text { Kualitatif }\end{array}$ \\
\hline
\end{tabular}




\begin{tabular}{|c|c|c|c|c|c|c|}
\hline No. & Tujuan & Variabel & Sub Variabel & Sumber Data & Cara Survei & Metode \\
\hline 3. & $\begin{array}{l}\text { Mengetahui } \\
\text { penyebab } \\
\text { masalah }\end{array}$ & $\begin{array}{c}\text { Permasala } \\
\text { han di } \\
\text { terminal }\end{array}$ & $\begin{array}{l}\text { - Persepsi } \\
\text { pemerintah, } \\
\text { penumpang dan } \\
\text { sopir bus } \\
\text { mengenai tingkat } \\
\text { pelayanan } \\
\text { terminal saat ini. } \\
\text { - Persepsi } \\
\text { pemerintah, } \\
\text { penumpang dan } \\
\text { sopir bus } \\
\text { terhadap } \\
\text { penyebab } \\
\text { permasalahan } \\
\text { yang terjadi di } \\
\text { terminal saat ini. }\end{array}$ & $\begin{array}{l}\text { - Hasil } \\
\text { wawancara } \\
\text { dengan } \\
\text { pemerintah, } \\
\text { penumpang } \\
\text { bus dan } \\
\text { sopir bus }\end{array}$ & $\begin{array}{l}\text { Survei } \\
\text { primer }\end{array}$ & $\begin{array}{l}\text { Analisa } \\
\text { Deskript } \\
\text { if } \\
\text { Kualitati } \\
\mathrm{f}\end{array}$ \\
\hline
\end{tabular}

\section{HASIL PENELITIAN}

Analisis Aspek Spasial

Analisis aspek spasial adalah analisis kesesuaian lokasi terminal dan penggunaan lahan di sekitar terminal saat ini dengan rencana tata ruang yang akan dijabarkan dalam tabel di bawah ini

Tabel 3 analisis spasial kesesuaian lahan

\begin{tabular}{|c|c|c|c|}
\hline No & $\begin{array}{c}\text { Rencana RTRW kab. } \\
\text { Gresik }\end{array}$ & Eksisting & Analisis \\
\hline 1 & $\begin{array}{l}\text { Adanya peningkatan kelas } \\
\text { terminal dari kelas C } \\
\text { menjadi Kelas B }\end{array}$ & 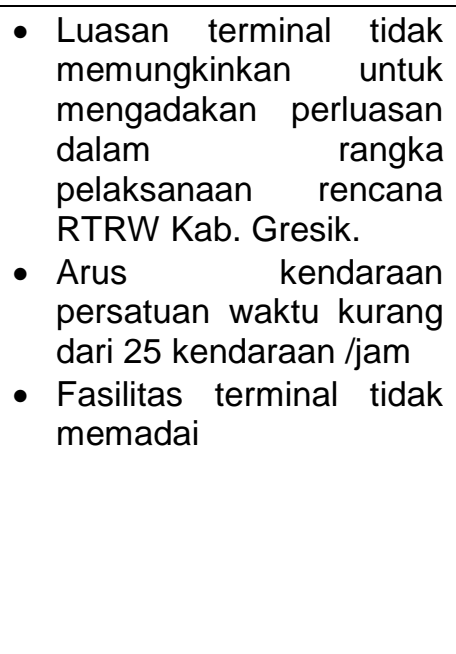 & $\begin{array}{l}\text { Syarat menjadi terminal } \\
\text { kelas B adalah : } \\
\text { - jumlah arus minimum } \\
\text { kendaraan persatuan } \\
\text { waktu adalah } 25-50 \\
\text { kendaraan. } \\
\text { - Fungsi terminal kelas B } \\
\text { melayani angkutan antar } \\
\text { kota dalam propinsi, } \\
\text { angkutan dalam kota } \\
\text { dan angkutan pedesaan. } \\
\text { - Selain fasilitas utama } \\
\text { sarana dan prasarana di } \\
\text { terminal kelas B di } \\
\text { lengkapi dengan fasilitas } \\
\text { pendukung }\end{array}$ \\
\hline 2 & $\begin{array}{ll}\text { Pembangunan } & \text { terminal } \\
\text { kargo di terminal Bunder } \\
\text { Gresik }\end{array}$ & $\begin{array}{l}\text { - Luasan terminal tidak } \\
\text { memadai. } \\
\text { - Area parker untuk } \\
\text { kargo tidak ada. } \\
\text { - Fasilitas pendukung } \\
\text { terminal kargo tidak } \\
\text { ada. }\end{array}$ & $\begin{array}{l}\text { - Terminal kargo adalah } \\
\text { termasuk dalam terminal } \\
\text { barang dimana } \\
\text { prasarana } \\
\text { transportasinya bagi } \\
\text { keperluan perpindahan } \\
\text { barang dan pengiriman } \\
\text { barang. } \\
\text { - Memerlukan area yang } \\
\text { sangat luas. } \\
\text { - Aksesbilitas tinggi }\end{array}$ \\
\hline
\end{tabular}

Analisis Aspek Teknis

Aspek analisis teknis adalah dengan menganalisis dari karakteristik penumpang dan tingkat pelayanan terminal.
1. Analisis Karakteristik Penumpang. Analisis karakteristik penumpang dilihat dari volume penumpang, waktu tunggu penumpang, pola pergerakan 
penumpang, frekuensi perjalanan dan keperluan perjalanan.

a. Volume penumpang

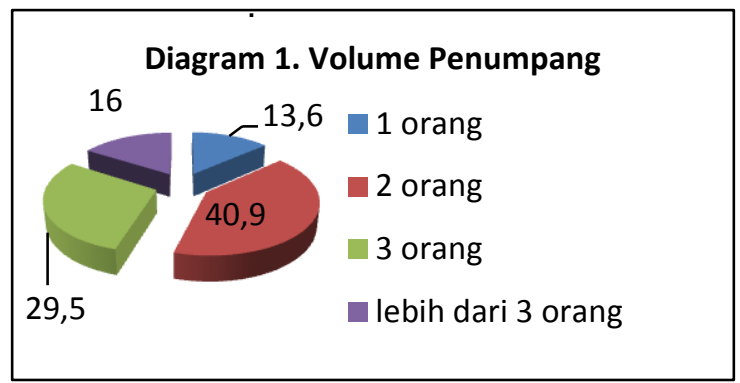

Dari hasil analisis volume penumpang, hamper separuh dari calon penumpang yang ada di ruang tunggu terminal $(40,9 \%)$ berjumlah 2 orang pengikut. sehingga diartikan bahwa setiap calon penumpang membawa 1 orang pengikut untuk bersama - sama melakukan perjalanan.

b. Waktu tunggu penumpang

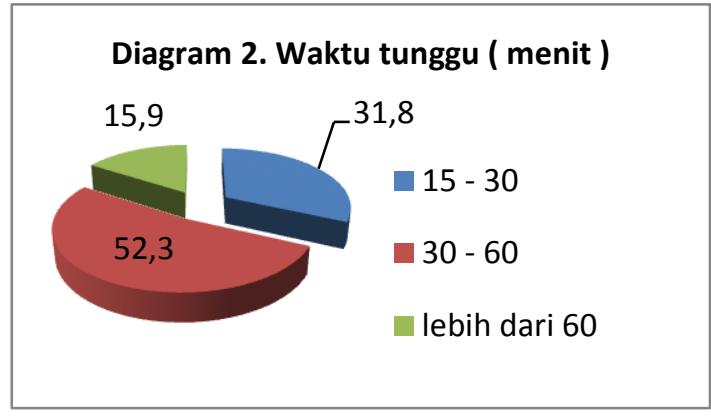

Data yang diperoleh berdasarkan pengisian kuisioner yang disebarkan ke 44 responden yang merupakan calon penumpang di ruang tunggu penumpang.

Dari hasil analisis waktu tunggu bus calon penumpang untuk mendapatkan bus yang diinginkan adalah lebih dari separuhnya $(52,3 \%)$ adalah 30 menit - 60 menit. Ini berarti waktu tunggu tidak terlalu lama untuk mendapatkan bus yang dituju.

c. Pola pergerakan penumpang

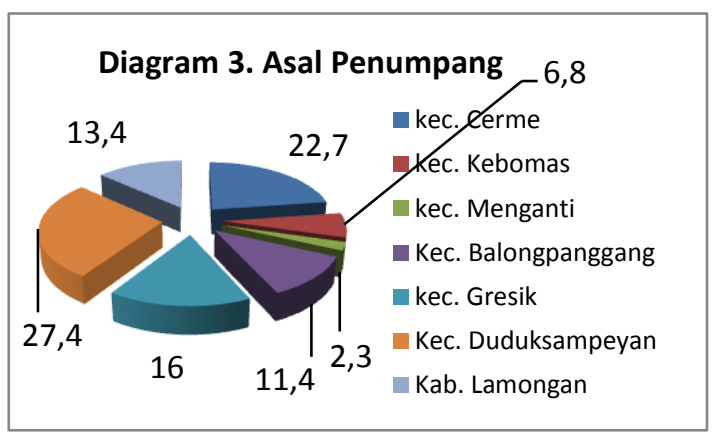

Data yang diperoleh berdasarkan pengisian kuisioner yang disebarkan ke 44 responden yang merupakan calon penumpang di ruang tunggu penumpang.

Dari hasil analisis asal calon penumpang yang ada di ruang tunggu terminal adalah $27.4 \%$ berasal dari Kecamatan Duduksampeyan. Sehingga apabila terjadi relokasi terminal di daerah Kecamatan Duduksampeyan sangatlah mendukung aktivitas pergerakan penduduknya.

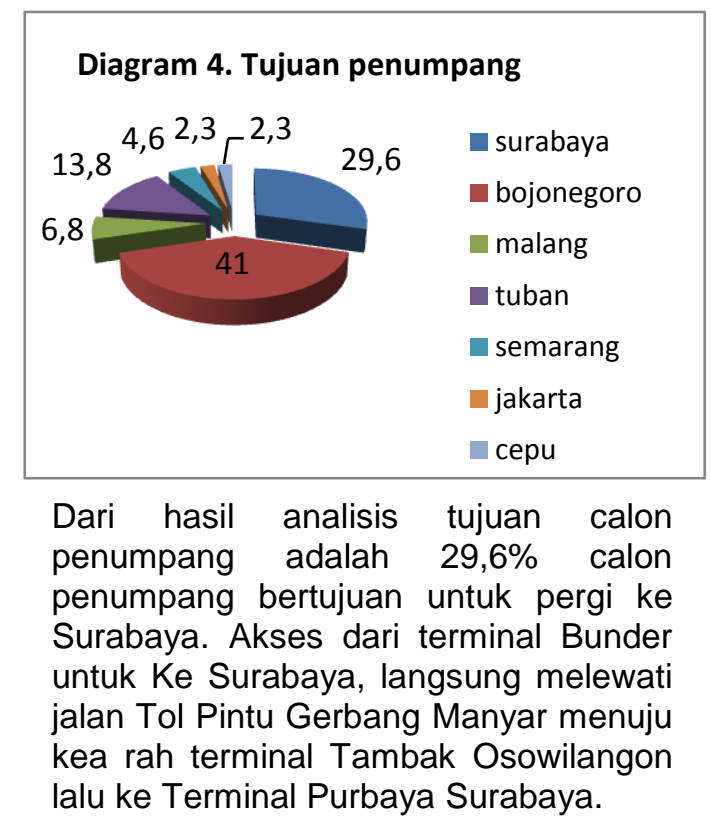

d. Frekuensi perjalanan

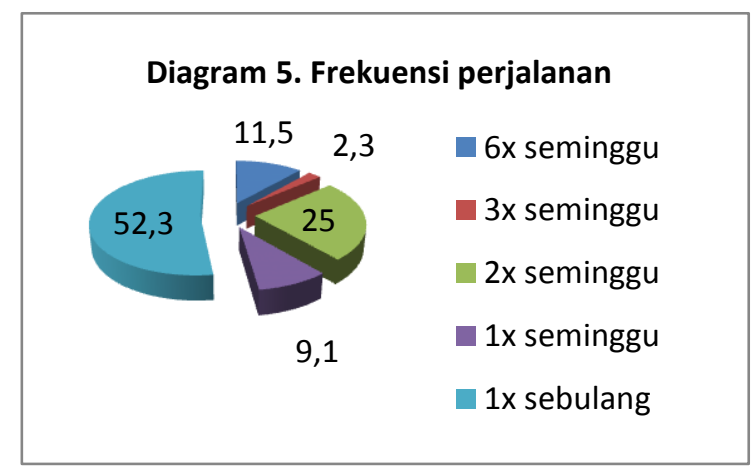

Data yang diperoleh berdasarkan pengisian kuisioner yang disebarkan ke 44 responden yang merupakan calon penumpang di ruang tunggu penumpang.

Dari hasil analisis frekuensi perjalanan di dapat $52.3 \%$ responden melakukan 
perjalanan dengan menggunakan jasa terminal Bunder.

e. Keperluan perjalanan

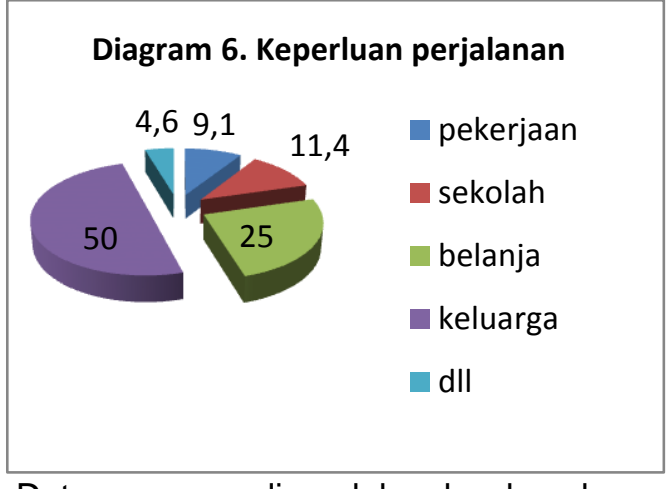

Data yang diperoleh berdasarkan pengisian kuisioner yang disebarkan ke 44 responden yang merupakan calon penumpang di ruang tunggu penumpang.

Dari hasil analisis keperluan penumpang dalam berpergian adalah separuh dari responden $(50 \%)$ mempunyai keperluan keluarga.

2. Analisis Tingkat pelayanan Terminal Analisis tingkat pelayanan terminal dilihat dari system sirkulasi datang dan pergi bus, fasilitas utama dan fasilitas penunjang.

1. Sistem sirkulasi datang dan pergi bus

System sirkulasi pergi dan datang bus dilihat dari Volume bus yang masuk ke terminal Bunder Gresik, dan waktu bus masuk dan keluar terminal.

a. Volume Bus

Rata - rata volume bus yang masuk adalah $111 \mathrm{~s} / \mathrm{d} 237$ bus dalam satu hari (24 jam) sehingga jika dianalisis dengan kelas terminal maka persatuan waktu bus yang masuk ke terminal Bunder Gresik adalah

$(111+237) / 2=174$ rata - rata jumlah bus yang masuk ke terminal

$174 / 24=7.24$ dibulatkan 8 (delapan) bus yang masuk ke terminal Bunder tiap satuan waktunya.

Sehingga dari hasil analisis maka terminal Bunder termasuk dalam terminal kelas $\mathrm{C}$

b. Waktu masuk dan keluar bus

Waktu bus masuk dan keluar terminal oleh peneliti di rangkum menjadi waktu lamanya bus berhenti di terminal untuk menurunkan penumpang dan menaikkan penumpang.

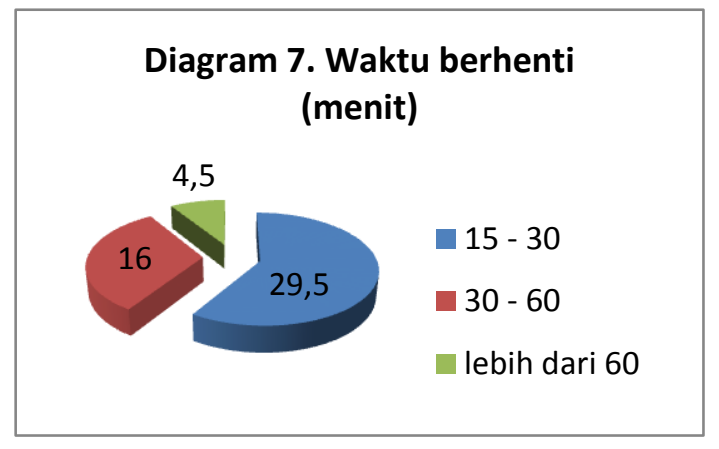

Dari hasil analisis waktu berhenti bus di terminal Bunder Gresik adalah $29,5 \%$ bus memerlukan waktu untuk berhenti menurunkan dan menaikan penumpang adalah $15-30$ menit.

3. Fasilitas terminal

Fasilitas terminal terbagi menjadi fasilitas utama dan fasilitas pendukung.

Fasilitas utama terdiri dari jalur pemberangkatan kendaraan umum, jalur kedatangan kendaraan umum, tempat parker kendaraan umum, bangunan kantor terminal, tempat tunggu calon penumpang dan pengantar, menara pengawas, loket penjualan tiket, penandaan, pelataran parker kendaraan.

Fasilits penunjang terdiri dari : kamar kecil/toilet, Musholah, kios / kantin, ruang pengobatan, ruang informasi dan pengaduan, telepon umum, tempat penitipan barang dan taman.

a. Fasilitas utama

Analisis fasilitas utama berdasarkan eksisting dengan peraturan yang ada, yang akan dijabarkan pada tabel 4 .

Tabel 4 analisis fasilitas utama terminal Bunder Gresik.

\begin{tabular}{llllll}
\hline no & Fasilitas utama & \multicolumn{2}{c}{ peraturan } & \multicolumn{2}{c}{ analisis } \\
\hline 1 & Jalur & Adanya pemisahan & Sudah terdapat pemisahan jalur \\
& pemberangkatan & antara jendaraan umum & pemberangkatan & jalur & kendaraan. \\
& & & & \\
\hline
\end{tabular}




\begin{tabular}{|c|c|c|c|}
\hline & & $\begin{array}{l}\text { untuk jalur bus, jalur } \\
\text { angkutan antar kota, } \\
\text { dan jalur kendaraan } \\
\text { pribadi } \\
\text { Adanya pemisahan }\end{array}$ & \\
\hline 2 & $\begin{array}{l}\text { Jalur kedatangan } \\
\text { kendaraan umum }\end{array}$ & $\begin{array}{l}\text { Adanya pemisahan } \\
\text { antara jalur } \\
\text { pemberangkatan } \\
\text { untuk jalur bus, jalur } \\
\text { angkutan antar kota, } \\
\text { dan jalur kendaraan } \\
\text { pribadi }\end{array}$ & $\begin{array}{l}\text { Sudah terdapat } \\
\text { kendaraan. }\end{array}$ \\
\hline 3 & $\begin{array}{l}\text { Tempat parker } \\
\text { kendaraan umum }\end{array}$ & $\begin{array}{l}\text { Luasan tempat parker } \\
\text { disesuaikan dengan } \\
\text { tipe terminal A, B dan } \\
\text { C }\end{array}$ & $\begin{array}{l}\text { Luasan sudah memadai, terdapat } \\
\text { perkerasan, tetapi tidak terdapat } \\
\text { pemisahan jalur kendaraan }\end{array}$ \\
\hline 4 & $\begin{array}{l}\text { Bangunan } \\
\text { terminal }\end{array}$ & $\begin{array}{l}\text { Terdapat bangunan } \\
\text { kantor terminal }\end{array}$ & $\begin{array}{l}\text { Sudah terdapat bangunan kantor } \\
\text { terminal bersebelahan dengan jalur } \\
\text { bus / platform/breth/bus way }\end{array}$ \\
\hline 5 & $\begin{array}{l}\text { Ruang tunggu calon } \\
\text { penumpang } \\
\text { pengantar }\end{array}$ & $\begin{array}{l}\text { Luasan tempat parker } \\
\text { disesuaikan dengan } \\
\text { tipe terminal A, B dan } \\
\text { C }\end{array}$ & $\begin{array}{l}\text { Sudah terdapat ruang tunggu, dengan } \\
\text { luasan yang sesuai dengan tipe C, } \\
\text { hanya keadannya yang kotor dan tidak } \\
\text { terawatt, kursi yang tersedia juga } \\
\text { terbatas lebih banyak di pakai istirahat } \\
\text { para pengasong. }\end{array}$ \\
\hline 6 & Menara pengawas & $\begin{array}{l}\text { Terdapat menara } \\
\text { pengawas }\end{array}$ & $\begin{array}{l}\text { Terdapat menara pengawas tetapi } \\
\text { tidak digunakan secara maksimal. } \\
\text { Jumlah menara pengawas ada } 2 \text {. Di } \\
\text { jalur kedatangan dan di jalur } \\
\text { keberangkatan. Tetapi yang hanya } \\
\text { digunakan hanya di jalur } \\
\text { keberangkatan, karena berfungsi } \\
\text { ganda sebagai tempat penarikan } \\
\text { retribusi bus. } \\
\text { Hal ini tidak sesuai dengan aturan } \\
\text { yang berlaku. }\end{array}$ \\
\hline 7 & $\begin{array}{l}\text { Loket } \\
\text { karcis }\end{array}$ & $\begin{array}{l}\text { Terdapat penjualan } \\
\text { karcis masuk }\end{array}$ & $\begin{array}{l}\text { Tidak terdapat loket penjualan karcis } \\
\text { masuk terminal. Hal ini tidak sesuai } \\
\text { dengan peraturan, sehingga dapat } \\
\text { menimbulkan percampuran antara } \\
\text { calon penumpang, pengantar dan } \\
\text { pedangan asongan }\end{array}$ \\
\hline 8 & Penandaan & $\begin{array}{l}\text { Jelas, mudah di baca } \\
\text { dan mudah } \\
\text { dimengerti }\end{array}$ & $\begin{array}{l}\text { Sudah terdapat penandaan di sekitar } \\
\text { lingkungan terminal, tetapi kurang } \\
\text { ditaati oleh para calon penumpang, } \\
\text { pengantar dan pengguna kendaraan } \\
\text { umum }\end{array}$ \\
\hline 9 & $\begin{array}{l}\text { Pelataran } \\
\text { kendaraan } \\
\text { pengantar }\end{array}$ & $\begin{array}{l}\text { Luasan tempat parker } \\
\text { disesuaikan dengan } \\
\text { tipe terminal A, B dan } \\
\text { C }\end{array}$ & $\begin{array}{l}\text { Sudah terdapat tempat parker untuk } \\
\text { kendaraan pengantar hanya letaknya } \\
\text { yang tertutup dan kurang jelas arah } \\
\text { penandaan untuk masuk dan keluar } \\
\text { kendaraan. }\end{array}$ \\
\hline
\end{tabular}

b. Fasilitas penunjang

Analisis penunjang berdasarkan keadaan eksisting dengan peraturan yang berlaku,yang akan dijabarkan pada tabel 5 
Tabel 5. analisis fasilitas penunjang terminal Bunder Gresik

\begin{tabular}{|c|c|c|c|}
\hline no & Fasilitas penunjang & peraturan & analisis \\
\hline 1 & Kamar kecil/toilet & $\begin{array}{l}\text { Berdasarkan keputusan } \\
\text { menteri perhubungan no. } \\
31 \text { tahun } 1995 \text { tentang } \\
\text { terminal transportasi jalan, } \\
\text { tercantum jenis - jenis } \\
\text { fasilitas umum yang } \\
\text { disesuaikan dengan tipe } \\
\text { terminal }\end{array}$ & $\begin{array}{l}\text { Kamar kecil/ toilet yang terdapat di } \\
\text { terminal Bunder berjumlah } 2 \text { buah, } \\
\text { keadaan kotor tidak terawatt } \\
\text { terkesan kumuh. } \\
\text { Terdapat pemungutan retribusi } \\
\text { untuk masuk ke toilet. }\end{array}$ \\
\hline 2 & Musholah & $\begin{array}{l}\text { Berdasarkan keputusan } \\
\text { menteri perhubungan no. } \\
31 \text { tahun } 1995 \text { tentang } \\
\text { terminal transportasi jalan, } \\
\text { tercantum jenis }- \text { jenis } \\
\text { fasilitas umum yang } \\
\text { disesuaikan dengan tipe } \\
\text { terminal }\end{array}$ & $\begin{array}{l}\text { Terdapat } 1 \text { (satu) Musholah } \\
\text { dengan luasan yang memadai. } \\
\text { Perletakan yang tidak sesuai } \\
\text { dengan peruntukannya karena } \\
\text { terletak di ujung jalur } \\
\text { keberangkatan kendaraan umum } \\
\text { sehingga tidak menjangkau dari } \\
\text { seluruh area terminal }\end{array}$ \\
\hline 3 & Kios/kantin & $\begin{array}{l}\text { Berdasarkan keputusan } \\
\text { menteri perhubungan no. } \\
31 \text { tahun } 1995 \text { tentang } \\
\text { terminal transportasi jalan, } \\
\text { tercantum jenis }- \text { jenis } \\
\text { fasilitas umum yang } \\
\text { disesuaikan dengan tipe } \\
\text { terminal }\end{array}$ & $\begin{array}{l}\text { Terdapat kios dan kantin. Banyak } \\
\text { kios di area parker kendaraan } \\
\text { pengantar yang tutup hal ini } \\
\text { dikarenakan jarangnya calon } \\
\text { pengantar yang menngunakan } \\
\text { kendaraan pribadi. }\end{array}$ \\
\hline 4 & Ruang pengobatan & $\begin{array}{l}\text { Berdasarkan keputusan } \\
\text { menteri perhubungan no. } \\
31 \text { tahun } 1995 \text { tentang } \\
\text { terminal transportasi jalan, } \\
\text { tercantum jenis - jenis } \\
\text { fasilitas umum yang } \\
\text { disesuaikan dengan tipe } \\
\text { terminal }\end{array}$ & $\begin{array}{l}\text { Tidak terdapat ruang pengobatan. } \\
\text { Tidak sesuai dengan peraturan. }\end{array}$ \\
\hline 5 & $\begin{array}{l}\text { Ruang informasi dan } \\
\text { pengaduan }\end{array}$ & $\begin{array}{l}\text { Berdasarkan keputusan } \\
\text { menteri perhubungan no. } \\
31 \text { tahun } 1995 \text { tentang } \\
\text { terminal transportasi jalan, } \\
\text { tercantum jenis }- \text { jenis } \\
\text { fasilitas umum yang } \\
\text { disesuaikan dengan tipe } \\
\text { terminal }\end{array}$ & $\begin{array}{l}\text { Terdapat ruang informasi dan } \\
\text { pengaduan tetapi letaknya di } \\
\text { dalam bangunan kantor terminal } \\
\text { sehingga tidak menjangkau } \\
\text { seluruh penumpang yang } \\
\text { memerlukan informasi. }\end{array}$ \\
\hline 6 & Telepon umum & $\begin{array}{l}\text { Berdasarkan keputusan } \\
\text { menteri perhubungan no. } \\
31 \text { tahun } 1995 \text { tentang } \\
\text { terminal transportasi jalan, } \\
\text { tercantum jenis - jenis } \\
\text { fasilitas umum yang } \\
\text { disesuaikan dengan tipe } \\
\text { terminal }\end{array}$ & $\begin{array}{l}\text { Terdapat telepon umum tetapi } \\
\text { tidak berfungsi }\end{array}$ \\
\hline 7 & $\begin{array}{l}\text { Tempat } \\
\text { barang }\end{array}$ & $\begin{array}{l}\text { Berdasarkan keputusan } \\
\text { menteri perhubungan no. } \\
31 \text { tahun } 1995 \text { tentang } \\
\text { terminal transportasi jalan, } \\
\text { tercantum jenis - jenis } \\
\text { fasilitas umum yang } \\
\text { disesuaikan dengan tipe } \\
\text { terminal }\end{array}$ & $\begin{array}{l}\text { Tidak terdapat tempat penitipan } \\
\text { barang }\end{array}$ \\
\hline 8 & Taman & Berdasarkan & Terdapat taman dalam terminal \\
\hline
\end{tabular}




\begin{tabular}{clll}
\hline no Fasilitas penunjang & \multicolumn{1}{c}{ peraturan } & \multicolumn{1}{c}{ analisis } \\
\hline & menteri perhubungan no. tetapi antara prosentase \\
& 31 tahun 1995 tentang perkerasan dengan jenis tanaman, \\
& terminal transportasi jalan, lebih banyak perkerasan di area \\
& tercantum jenis - jenis terminal. Tanamana yang \\
& fasilitas umum yang mendominasi adalah tanaman \\
& disesuaikan dengan tipe dengan jenis produktif (tanaman \\
& terminal & jati dan asem) \\
\hline
\end{tabular}

\section{Permasalahan di Terminal}

Untuk mendapatkan permasalahan di terminal merangkum dan menganalisis dari hasil wawancara pemerintah, penumpang bus dan sopir bus.

Berdasarkan persepsi pemerintah, penumpang dan sopir bus dan juga dari hasil observasi dan penyebaran kuisioner, maka dianalisis permasalahan yang ada di terminal dijabarkan pada tabel 6 dibawah ini

Tabel 6 persepsi pemerintah, penumpang dan sopir bus permasalahan di terminal

\begin{tabular}{|c|c|c|c|c|c|}
\hline no & Variable & Persepsi pemerintah & Persepsi penumpang & Persepsi sopir bus & analisis \\
\hline 1 & $\begin{array}{l}\text { Tingkat } \\
\text { pelayana } \\
\mathrm{n} \text { terminal }\end{array}$ & 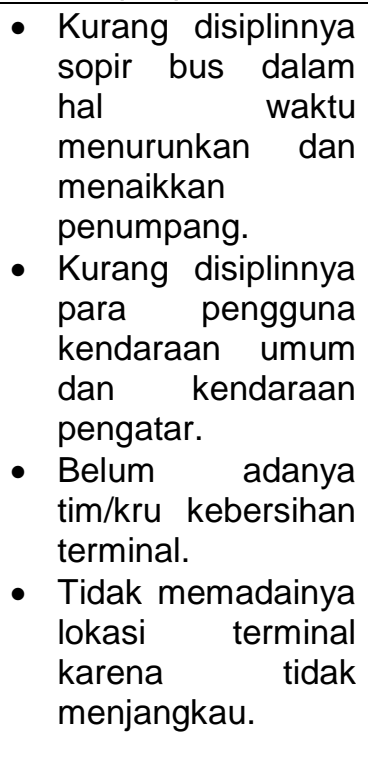 & $\begin{array}{l}\text { - Waktu tunggu bis } \\
\text { yang lama } \\
\text { - Ruang tunggu yang } \\
\text { kotor dan tidk aman } \\
\text { karena banyak } \\
\text { pedangan asongan } \\
\text { - Toilet yang kotor } \\
\text { dan air tidak } \\
\text { mengalir dengan } \\
\text { lancer } \\
\text { Kurang } \\
\text { bervariasinya } \\
\text { pedagang kios } \\
\text { kantin di ruang } \\
\text { tunggu penumpang. } \\
\text { Waktu kedatangan } \\
\text { dan keberangkatan } \\
\text { bus yang tidak } \\
\text { jelas. }\end{array}$ & $\begin{array}{l}\text { - Sedikitnya } \\
\text { jumlah } \\
\text { penumpang } \\
\text { yang turun dan } \\
\text { naik ke bus. } \\
\text { - Waktu tunggu } \\
\text { bus untuk } \\
\text { mencari } \\
\text { penumpang } \\
\text { kurang } \\
\text { - Jalur masuk ke } \\
\text { terminal yang } \\
\text { harus memutar. }\end{array}$ & $\begin{array}{lr}\text { Analisis } & \text { tingkat } \\
\text { pelayanan } & \text { di } \\
\text { terminal } & \text { Bunder } \\
\text { Gresik } & \text { masih } \\
\text { belum maksimal, } \\
\text { hal ini dilihat dari } \\
\text { masih banyak } \\
\text { keluhan dari pihak } \\
\text { pemerintah, } \\
\begin{array}{l}\text { penumpang dan } \\
\text { sopir bus. }\end{array}\end{array}$ \\
\hline 2 & $\begin{array}{l}\text { Permasal } \\
\text { ahan } \\
\text { yang ada } \\
\text { di } \\
\text { terminal }\end{array}$ & $\begin{array}{l}\text { - Kurangnya activity } \\
\text { support di sekitar } \\
\text { lingkungan } \\
\text { terminal }\end{array}$ & $\begin{array}{l}\text { - Sarana dan } \\
\text { prarasana / fasilitas } \\
\text { terminal yang tidak } \\
\text { memadai }\end{array}$ & $\begin{array}{l}\text { - Kurangnya } \\
\text { calon } \\
\text { penumpang } \\
\text { untuk } \\
\text { menggunakan } \\
\text { jasa bus }\end{array}$ & $\begin{array}{l}\text { Analisis } \\
\text { permasalahan } \\
\text { terminal adalah } \\
\text { kurangnya activity } \\
\text { support yang } \\
\text { termasuk di } \\
\text { dalamnya } \\
\text { peningkatan } \\
\text { fasilitas terminal, } \\
\text { yang dapat } \\
\text { meningkatkan } \\
\text { animo masyarakat } \\
\text { untuk pergi ke } \\
\text { terminal dan } \\
\text { menggunakan jasa } \\
\text { angkutan umum }\end{array}$ \\
\hline
\end{tabular}

\section{PEMBAHASAN}

Hasil dari analisis kesesuaian lahan terminal dengan Rencana RTRW kab. Gresik adalah Tidak Sesuai. Sehingga perlu relokasi terminal Bunder ke lahan yang lebih luas dengan pertimbangan sebagai berikut : aksesbilitas yang tinggi : 
1. sesuai dengan rencana umum tata ruang

2. kapasitas jalan

3. keterpaduan dengan transportasi lain

4. tetap memperharikan kelestarian lingkungan

5. terletak di daerah pinggir kota yang sentries sesuai dengan arah geografis lokasi pemasaran regional.

Memacu pada hal - hal diatas maka rekomendasi relokasi terminal Bunder Gresik berada di area kecamatan Duduksampeyan kabupaten Gresik. Selain untuk terminal penumpang juga dapat dikembangakan untuk terminal kargo. Didukung dengan adanya activity support yaitu stasiun Kereta Api jalur Surabaya, Gresik, Lamongan, Mojokerto.

Pembahasan aspek Teknis

1. Pemberian penandaan berupa pintu gerbang / tugu untuk memperjelas jalr untuk kendaraan

2. Perlu adanya pemisahan jalur kendaraan sehingga kendaraan umum yang masuk lebih teratur, juga calon penumpang lebih mengerti dan mudah mendapatkan jalur kendaraan yang dituju

3. Perlu adanya pembatasan antara calon penumpang dengan pedagang asingan.

4. Perlu adanya tim kebersihan terminal Bunder Gresik dan juga menambahkan jumlah bak / tong sampah.

5. Perlu difungsikan kembali menara pengawas sesuai dengan fungsinya.

6. Perlu adanya loket penjualan karcis

7. Perlu adanya pengawasan di jalur jalur tertentu, terutama jalur bus. Agar tidak membahayakan calon penumpang.

8. Perlu adanya penandaan yang jelas.

Rekomendasi dari seluruh permasalahan yang sudah dianalisis adalah :

1. Peningkatan pelayanan terminal bunder gresik dengan menambahkan fasilitas utama dan fasilitas penunjang terminal bunder.

2. Perlu adanya pemeliharaan secara berkelanjutan bagi fasilitas yang ada di terminal.

3. Perlu adanya activity support untuk mendukung / meningkatkan animo masyarakat untuk datang ke terminal Bunder dan menggunakan jasa angkutan umum.
4. Khusus untuk terminal bunder dikarenakan lokasi / area yang sekarang sudah tidak bisa dikembangkan lagi maka perlu relokasi terminal bunder ke tempat lain.

5. Perlunya manajemen pelayanan terminal yang jelas dan transparan dalam usaha meningkatkan pelayanan terminal.

\section{SIMPULAN DAN SARAN}

Kesimpulan dari kompilasi data yang diperoleh dari lapangan adalah :

Kinerja operasional terminal Bunder Gresik

a. Dilihat dari karakteristik penumpang Volume penumpang yang masuk ke terminal berjumlah 2 (dua) orang $(40,9) \%$, waktu tunggu 30 menit -60 menit $(52,3 \%)$, asal penumpang dari kecamatan Duduksampeyan $(27,4 \%)$, tujuan penumpang ke Surabaya $(29,6 \%)$, frekuensi perjalanan 1x perbulan $(52,3 \%)$ dan keperluan perjalanan untuk kepentingan keluarga (50\%). Sehingga bias disimpulkan pelayanan terminal Bunder dari sisi calon penumpang masih kurang. Kelancarannya, frekuens perjalanan, waktu tunggu dan kepentingan perjalanan masih belum menyangkup secara menyeluruh.

b. Dilihat dari aspek kesesuaian fasilitas terminal

Kesesuaian fasilitas terminal dilihat dari peraturan dan eksisting yang ada masih banyak yang tidak sesuai kelengkapannya, seperti ruang loket masuk, ruang informasi, taman, ruang penitipan barang dan ruang pengobatan.

c. Dilihat dari aspek spasial

Tipe terminal Bunder sekarang adalah tipe $\mathrm{C}$ yang dalam rencana RTRW akan ditingkatkan menjadi terminal tipe $\mathrm{B}$ dengan tambahan sebagai terminal Kargo. Hasil analisis aspek spasial, tidak sesuai peruntukkan lahannya sebagai terminal tipe $B$ sehingga perlu relokasi tempat terminal di kawasan kecamatan Duduksampeyan. Kebijakan lokasi dilihat dari aspek aksesbilitas, dan activity support yang mendukung seperti berada di kawasan perdagangan dan stasiun kereta api.

d. Dilihat dari kelancaran pengaturan sirkulasi datang dan berangkat bus 
Volume bus yang masuk per satuan waktu adalah 8 bus/jam sehingga saat ini dikateforikan masuk terminal tipe C.
Waktu yang dibutuhkan masuk keluar terminal adalah 15 menit - 30 menit sehingga bias di kategorikan pengaturan sirkulasi datang dan berangkat bus adalah lancar.

\section{DAFTAR PUSTAKA}

Abubakar I. (1997), Menuju Lalu Lintas dan Angkutan Jalan yang Tertib, Edisi yang disempurnakan, Direktorat Jendral Perhubungan Darat, Jakarta.

Santoso, I. (1996), Perencanaan Prasarana Angkutan Umum, Pusat Studi Transportasi dan Komunikasi, ITB.

Warpani, Suwardjoko (1990), Merencanakan Sistem Perangkutan, Jakarta.

Morlok (1991), Pengantar Teknik dan Perencanaan Transportasi, Penerbit Erlangga, Jakarta.

Tamin O.Z. (2000), Perencanaan dan Pemodelan Transportasi, Edisi Kedua, Penerbit ITB, Bandung.

Anonim (1997), Rekayasa Lalu Lintas; Pedoman Perencanaan dan Pengoperasian Lalu Lintas di Wilayah Perkotaan, Direktorat Jendral Perhubungan Darat.

Nazir, Mohammad (1999), Metode Penelitian, Edisi Keempat, Penerbit Ghalia Indonesia, Jakarta Diyan Fatimah (2004), studi evaluasi kinerja terminal bus Bunder di Kabupaten Gresik, Skripsi Perencanaan Wilayah dan Kota Universitas Brawijaya Malang.

Kep. Men.Hub. No.KM/31/Tahun 1995 tentang Terminal transportasi Jalan 